\title{
WHY DO SOME SOCIAL INSECT QUEENS MATE WITH SEVERAL MALES? TESTING THE SEX-RATIO MANIPULATION HYPOTHESIS IN LASIUS NIGER
}

\author{
Else J. Fuerdingstad, ${ }^{1,2}$ Pia J. Gertsch, ${ }^{3,4}$ and Laurent Keller ${ }^{1}$ \\ ${ }^{1}$ Department of Zoology and Animal Ecology, Institute of Ecology, University of Lausanne, CH-1015 Lausanne, Switzerland \\ ${ }^{3}$ Department of Conservation Biology and Genetics, Evolutionary Biology Centre, Uppsala University, Norbyvägen 18 D, \\ S-752 36 Uppsala, Sweden
}

\begin{abstract}
Although multiple mating most likely increases mortality risk for social insect queens and lowers the kin benefits for nonreproductive workers, a significant proportion of hymenopteran queens mate with several males. It has been suggested that queens may mate multiply as a means to manipulate sex ratios to their advantage. Multiple paternity reduces the extreme relatedness value of females for workers, selecting for workers to invest more in males. In populations with female-biased sex ratios, queens heading such male-producing colonies would achieve a higher fitness. We tested this hypothesis in a Swiss and a Swedish population of the ant Lasius niger. There was substantial and consistent variation in queen mating frequency and colony sex allocation within and among populations, but no evidence that workers regulated sex allocation in response to queen mating frequency; the investment in females did not differ among paternity classes. Moreover, population-mean sex ratios were consistently less female biased than expected under worker control and were close to the queen optimum. Queens therefore had no incentive to manipulate sex ratios because their fitness did not depend on the sex ratio of their colony. Thus, we found no evidence that the sex-ratio manipulation theory can explain the evolution and maintenance of multiple mating in L. niger.
\end{abstract}

Key words.-Ants, kin selection, multiple mating, sex-ratio manipulation, social insects.

Received May 2, 2001. Accepted September 20, 2001.

Although multiple mating by females probably often incurs costs and no obvious benefits, it has been reported for a wide range of taxa (Keller and Reeve 1995; Birkhead and Møller 1998; Jennions and Petrie 2000). In social insects, multiple mating by queens occurs in many species (Boomsma and Ratnieks 1996), even though a single mating usually provides enough sperm to cover the lifetime requirements of a queen (but see Cole 1983; Fjerdingstad and Boomsma 1998) and mating with several males is likely to increase mortality risk. The significant incidence of multiple mating in social insects is particularly puzzling because multiple paternity reduces the relatedness of workers to the brood they rear, thus decreasing the incentive for workers to forego their own reproduction (Hamilton 1964).

Several hypotheses have been put forward to account for the evolution and maintenance of multiple mating in social Hymenoptera. Most of these hypotheses propose that polyandry may be advantageous to queens because of the resultant increase in genetic variability within colonies. Such variability may, for example, enhance disease resistance or worker force efficiency (Keller and Reeve 1994; reviews by Bourke and Franks 1995; Boomsma and Ratnieks 1996; Crozier and Pamilo 1996; Schmid-Hempel 1998). Although the theoretical advances have been considerable in the last decades, empirical tests of these hypotheses have lagged behind. Moreover, test results have often been negative, inconclusive or inconsistent across species (Bourke and Franks 1995; Boomsma and Ratnieks 1996; Crozier and Pamilo 1996; Fjerdingstad et al. 1998; Kraus and Page 1998; Schmid-

\footnotetext{
2 Present address: Department of Genetics and Ecology, Institute of Biological Sciences, University of Aarhus, Ny Munkegade Building 540, DK-8000 Aarhus C, Denmark; E-mail: Else. Fjerdingstad@biology.au.dk

${ }^{4}$ Present address: Department of Population Ecology, Institute of Zoology, University of Copenhagen, Universitetsparken 15, DK2100 Copenhagen $\varnothing$, Denmark.
}

Hempel 1998; Sherman et al. 1998; Cole and Wiernasz 1999; Fjerdingstad and Keller 2000; Crozier and Fjerdingstad 2001) or have been obtained using systems with artificial levels of genetic diversity (e.g., Baer and Schmid-Hempel 1999). It thus remains unclear why social insect queens frequently mate with several males (Crozier and Fjerdingstad 2001).

A recent hypothesis, the sex-ratio manipulation hypothesis, proposes that queens mate multiply to induce workers to produce a more favorable sex ratio (Moritz 1985; Pamilo 1991; Queller 1993; Ratnieks and Boomsma 1995). Due to their haplodiploid sex determination system, hymenopteran workers are three times more related to their full sisters than to their brothers and should therefore invest three times more resources in females than in males to maximize their own inclusive fitness (Trivers and Hare 1976). A female-biased sex ratio is detrimental to queen fitness because queens are equally related to their sons and daughters and favor an equal investment in the two sexes. Multiple paternity lowers the relatedness asymmetry because it decreases the relatedness between nestmate females but does not affect the relatedness of males to workers. Workers would thus benefit by producing only or mainly males in colonies headed by multiply mated queens and mainly females in colonies headed by singly mated queens (split sex ratio theory, Boomsma and Grafen 1991). If the population sex ratio is female biased (as predicted if workers control sex ratios), queens in colonies specializing on male production have a higher fitness than do queens in female-producing colonies (Ratnieks and Boomsma 1995). Thus, multiple mating may confer an advantage to queens if workers respond to it by increasing the relative investment in male production.

The sex-ratio manipulation theory has only been tested once, in the ant Formica truncorum. In this ant Sundström and Ratnieks (1998) found that multiply mated queens had a 1.37 times higher fitness than singly mated queens because their colonies tended to produce a male-biased sex ratio. 
However, it was already known that workers of this species shift sex allocation according to the mating frequency of queens (Sundström 1994). The aim of the present study was to test the general explanatory power of the sex-ratio manipulation hypothesis in an ant system where it is unknown whether workers manipulate colony sex ratios according to queen mating frequency. We selected the garden ant Lasius niger because previous allozyme studies demonstrated that multiple mating occurs in this species and, intriguingly, that queen mating frequencies vary significantly between populations (van der Have et al. 1988; Boomsma and van der Have 1998). Earlier studies also reported that the populationmean sex ratio seemed to be under worker control in Dutch populations (van der Have et al. 1988). However, it had not been investigated whether workers are able to assess the relatedness asymmetry of their own colony and bias colonylevel investment patterns accordingly. In the hope of capturing among-population variation, we investigated two geographically distant populations, one in Switzerland and one in Sweden, using these as independent replicates. To further test the repeatability of our results, we replicated our test the following year for one of the two populations.

\section{Materials And Methods}

\section{The Organism}

Lasius niger is a small, very common, soil-nesting European ant (Boomsma et al. 1982; Seifert 1996) often found on meadows. Colonies are perennial and large (Boomsma et al. 1982), each headed by a single, large queen (van der Have et al. 1988; this study). In the reproductive season, L. niger colonies release thousands of young males and hundreds of queens (Boomsma et al. 1982; this study) that disperse on large-scale nuptial flights. After mating, queens start new colonies on their own, whereas males die.

\section{Sampling}

Nests were located in April-June (Lausanne, Switzerland, 1997 and 1998) or July (Uppsala, Sweden, 1997) on meadows of the campus of the University of Lausanne and close to the Department of Genetics at Uppsala University and the Uppsala Biomedical Centre at Ultuna and Kåbo, respectively. Taxonomical examination of workers and gynes (young unmated queens) confirmed that we only collected L. niger and not its close congener L. platythorax (Seifert 1996).

Workers and sexuals were collected by trapping (Lausanne) and excavation (Uppsala). Traps consisted of plastic web tents each covering a nest. In 1997 in Lausanne we collected all sexuals leaving nests for all 10 mating flights of that reproductive season (June-August). In 1998 we collected all sexuals from nine mating flights. In total we collected sexuals from 28 and 34 colonies in 1997 and 1998, respectively (also, five males were collected for each of two other colonies in 1997). Excavations (Uppsala) were carried out for at least two consecutive days for each nest. Fifty-two colonies were excavated; all sexuals were collected for 33 of these colonies. All ants were frozen at $-20^{\circ} \mathrm{C}$ after collections.

For each colony, we estimated the sex ratio. In Lausanne all gynes were counted and the number of males in $25 \%$ of the total mass of males was counted; in Uppsala total masses of males and females were divided by the average male or female weight, respectively, these average values being estimated by weighing five to 10 males and five to 10 females from each colony. In Lausanne dry weights of five gynes and five males per colony were determined after individuals had been oven-dried at $80^{\circ} \mathrm{C}$ for $48 \mathrm{~h}$. Gyne:male dry weight ratios were converted into specific energetic cost ratios using Boomsma and Isaaks's (1985) exponent, which corrects for the differential metabolic rates of the two sexes. Colony reproductive outputs were estimated from the dry weight biomass of sexuals, corrected for metabolic rate differences. In Uppsala excavations took place before sexuals reached maturity. We therefore used the gyne:male cost ratio (7.66) reported by Boomsma and Isaaks (1985) for a Dutch population of $L$. niger, a ratio that was identical to the average ratio for the Lausanne samples. Total productivity was estimated as for Lausanne except that Boomsma et al.'s (1982) estimate of gyne dry weight $(15.45 \mathrm{mg}$ ) was used (Lausanne estimates were $16 \mathrm{mg}$ and $13.4 \mathrm{mg}$ for 1997 and 1998, respectively).

\section{Laboratory Procedures}

We used two microsatellite loci, L10-282 and L10-53 (P. J. Gertsch, E. J. Fjerdingstad, and L. Keller, unpubl. ms.) and assessed the genotype for each colony (whenever possible) of five males and 20 gynes in Lausanne and 10 females and 10 males in Uppsala. For the colonies that produced no gynes (one colony for each of Lausanne 1997, 1998, and Uppsala) or only insufficient numbers of gynes (four, one, and 12 additional colonies) we assessed the genotype of workers. Standard proteinase K/SDS and phenol-chloroform (Lausanne) or Chelex (Bio-Rad, Clinical Diagnostics, Sundbyberg, Sweden) (Uppsala) methods were used to extract DNA from body parts of individual ants (heads of sexuals and entire bodies of workers in Lausanne, mesothoraces of workers and flight muscle tissue of sexuals in Uppsala). The final suspension volume was 100 or $200 \mu \mathrm{l}$ of $\mathrm{ddH}_{2} \mathrm{O}$ (Lausanne) and $200 \mu \mathrm{l}$ of Chelex mixture (Uppsala). The polymerase chain reaction (PCR) conditions were: Lausanne: $1 \times$ reaction buffer (Eurobio, Les Ulis, France), 0.6 and $1.2 \mathrm{mM}$ $\mathrm{Mg}^{2+}$ (L10-53 and L10-282, respectively), $76 \mu \mathrm{M} \mathrm{dCTP/}$ GTP/TTP, $7.6 \mu \mathrm{M}$ dATP, $0.02 \mu \mathrm{Ci} / \mu 1 \alpha-{ }^{33} \mathrm{P}-\mathrm{dATP}, 50 \mathrm{nM}$ each primer, $200 \mathrm{ng} / \mu \mathrm{l} \mathrm{BSA}, 0.06 \mathrm{U} / \mu \mathrm{l} \mathrm{DNA}$ polymerase (Eurobio), and $1 \mu$ l DNA suspension; Uppsala: 1x reaction buffer (MBI Fermentas, Tamro Medlab, Molndal, Sweden), 1.0-1.5 mM $\mathrm{Mg}^{2+}, 75 \mu \mathrm{M} \mathrm{dCTP} / \mathrm{GTP} / \mathrm{TTP}, 6 \mu \mathrm{M} \mathrm{dATP}$, $0.0125 \mu \mathrm{Ci} / \mu \mathrm{l} \alpha-{ }^{33} \mathrm{P}-\mathrm{dATP}, 400 \mathrm{nM}$ each primer, $20 \mathrm{ng} / \mu \mathrm{l}$ BSA, $0.04 \mathrm{U} / \mu \mathrm{l}$ DNA polymerase (MBI), and $1 \mu \mathrm{l}$ Chelex extract. The final amplification volumes were $10 \mu \mathrm{l}$.

PCR programs consisted of: Lausanne: a 3-min initial denaturation at $94^{\circ} \mathrm{C}$, followed by 15 or 26 cycles of 45 -sec steps at denaturation temperature $94^{\circ} \mathrm{C}$, annealing at 66 or $65^{\circ} \mathrm{C}-0.5^{\circ} \mathrm{C} /$ cycle (touch-downs), and elongation at $72^{\circ} \mathrm{C}$, followed by 24 or 13 cycles of 45 -sec steps at denaturation temperature $94^{\circ} \mathrm{C}$, annealing at 58 or $52^{\circ} \mathrm{C}$, and elongation at $72^{\circ} \mathrm{C}$; the same program was used for both loci; Uppsala: a 3-min initial denaturation at $94^{\circ} \mathrm{C}$, followed by 35 cycles with 30-sec steps at denaturation temperature $94^{\circ} \mathrm{C}$, annealing 
TABLE 1. Sample sizes and basic information on the microsatellite DNA markers used for the genetic offspring analyses on Lasius niger.

\begin{tabular}{|c|c|c|c|c|c|c|c|c|c|}
\hline \multirow[b]{2}{*}{ Population } & \multirow{2}{*}{$\begin{array}{c}\text { Number } \\
\text { of } \\
\text { colonies } \\
\text { analyzed }\end{array}$} & \multirow{2}{*}{$\begin{array}{l}\text { Average number } \\
\text { of females } \\
\text { and males } \\
\text { genotyped per } \\
\text { colony }^{1}\end{array}$} & \multirow{2}{*}{$\begin{array}{l}\text { Number } \\
\text { of } \\
\text { colonies } \\
\text { for sex } \\
\text { alloca- } \\
\text { tion }\end{array}$} & \multicolumn{2}{|c|}{ Number of alleles } & \multicolumn{2}{|c|}{$\begin{array}{c}\text { Observed } \\
\text { heterozygosity }\end{array}$} & \multicolumn{2}{|c|}{$\begin{array}{c}\text { Expected } \\
\text { heterozygosity }\end{array}$} \\
\hline & & & & L10-53 & L10-282 & L10-53 & L10-282 & L10-53 & L10-282 \\
\hline Lausanne 1997 & 28 & $19.4 / 5.0$ & 28 & 30 & 21 & 0.96 & 0.89 & 0.94 & 0.92 \\
\hline Lausanne 1998 & 34 & $19.8 / 5.0$ & 34 & 25 & 20 & 0.91 & 0.97 & 0.92 & 0.92 \\
\hline Uppsala & 52 & $10.0 / 8.8$ & 33 & 26 & 22 & 0.94 & 0.85 & 0.91 & 0.90 \\
\hline
\end{tabular}

${ }^{1}$ The number of males is per male-producing colony.

${ }^{2}$ Based on the inferred mother queen genotypes.

${ }^{3}$ Expected at Hardy-Weinberg equilibrium based on the combined maternal-paternal allele frequencies.

at $55^{\circ} \mathrm{C}$, and elongation at $72^{\circ} \mathrm{C}$. The final elongations were extended to $10 \mathrm{~min}$.

PCR products were run on denaturing $6 \%$ polyacrylamid gels at $2000 \mathrm{~V}$ for $4 \mathrm{~h}$ (L10-282) or $3 \mathrm{~h}$ (L10-53; Lausanne) or for $5000 \mathrm{Vh}$ (Uppsala). Individuals of known genotypes were run as standards for each 20 samples across the gel. After drying, gels were incubated with X-ray films for 1-3 days. The microsatellite markers were extremely polymorphic with heterozygosities close to or above 0.90 (Table 1).

\section{Genetic Analyses}

Maternal and paternal genotypes were reconstructed on the basis of the two-locus genotypes of female offspring (gynes or workers) as in Fjerdingstad et al. (1998). All these genotypes were compatible with monogyny except for Lausanne colonies C19 and C39, in which a single offspring's genotype was incompatible with the inferred mother queen, and $\mathrm{C} 23$, in which the genetic structure could not be resolved.

From the pedigree data, the effective number of mates per queen and nestmate relatedness were estimated as in Fjerdingstad et al. (1998) but applying Pedersen and Boomsma's (1999) sample size correction to Uppsala data. Sample size correction affected our results very little (Table 2). Nondetection error (cf. Pamilo 1993) was below 0.009 for all samples (Table 2) and the combined sample-size and nondetection error for Uppsala was only 0.043 , so that the estimated true frequency of double-mated queens in Uppsala was only $4 \%$ higher than the observed frequency (Table 2). The assumptions of random mating and no linkage disequilibrium between marker loci implicit in Pamilo's (1993) method were verified as in Fjerdingstad et al. (1998) using the program GENEPOP 3.1 (Raymond and Rousset 1995, 1997) and through identity-by-descent (IBD) relatedness analyses
(Queller and Goodnight 1989; see below) of queen-mate and mate-mate relatedness, as well as through exact binomial tests (Zar 1996, p. 532) and $\chi^{2}$-tests (Sokal and Rohlf 1995, pp. 694-697) for Mendelian segregation in the offspring of heterozygous queens.

The average regression-relatedness (Bourke and Franks 1995; Crozier and Pamilo 1996) among nestmate females, $r_{f f}$, was also estimated directly through IBD analyses using the program RELATEDNESS 5.05 (Goodnight 1999), whose algorithms compare the genetic similarity of individuals, their colonies, and the background population. We weighted all colonies equally in the analyses. From the IBD relatedness estimates we derived independent estimates of the effective number of mates per queen, using Page's (1986) equation 2.

In a few cases male offspring contained alleles not found in the inferred queen but found among the female offspring (i.e., paternal alleles of the workers), indicating that they were worker produced. We divided the observed frequency of worker reproduction by the detection probability estimated as:

$$
1-\left[\left(0.5 \cdot 1+0.5 \cdot \sum p_{i}^{2}\right) \cdot\left(0.5 \cdot 1+0.5 \cdot \sum t_{j}^{2}\right)\right]
$$

which is equal to $1-$ [(the probability that the worker transmits its maternal allele, in which case worker reproduction cannot be distinguished from queen reproduction, or the probability that a paternal allele is transmitted and the mother and the father by chance shared the transmitted allele for that locus) $\times$ (the same for the other locus)], where $p$ and $t$ denote the two different marker loci and $\Sigma p_{i}^{2}$ denotes the sum of squared frequencies of alleles at locus $p$, etc.

The relatedness of males to workers, $r_{m f}$, was also estimated directly through IBD analyses and used to estimate $q_{I B D}$ :

TABLE 2. Frequency of multiple mating by queens and the genetic effectiveness of multiple paternity in the three Lasius niger samples.

\begin{tabular}{|c|c|c|c|c|c|c|c|}
\hline \multirow[b]{2}{*}{ Population } & \multirow{2}{*}{$\begin{array}{c}\text { Number of } \\
\text { colonies }\end{array}$} & \multirow{2}{*}{$\begin{array}{c}\% \text { queens } \\
\text { that mated } \\
\text { multiply }\end{array}$} & \multirow{2}{*}{$\begin{array}{l}\text { Absolute } \\
\text { number of } \\
\text { fathers } \\
\text { (range) }\end{array}$} & \multicolumn{3}{|c|}{ Effective number of fathers } & \multirow{2}{*}{$\begin{array}{c}\text { Patriline } \\
\text { nondetection } \\
\text { error }^{1}\end{array}$} \\
\hline & & & & \multicolumn{2}{|c|}{ Pedigree } & \multirow{2}{*}{$\frac{\text { IBD }}{1.39}$} & \\
\hline Lausanne 1997 & 27 & 59.3 & $1.74(1-4)$ & 1.30 & $1.32^{2}$ & & 0.005 \\
\hline Lausanne 1998 & 34 & 61.8 & $1.71(1-3)$ & 1.30 & $1.32^{2}$ & 1.30 & 0.007 \\
\hline Uppsala & 52 & $13.5^{3}$ & $1.13(1-2)$ & 1.06 & $1.07^{2}$ & 1.04 & 0.009 \\
\hline
\end{tabular}

${ }^{1}$ The probability that two paternal males carry the same two-locus marker genotype and thus are genetically undistinguishable (Pamilo 1993).

${ }^{2}$ Lausanne data sample-size corrected according to Pamilo (1993); Uppsala data sample-size and nondetection corrected according to Pedersen and Boomsma (1999).

${ }^{3}$ Correcting for sample size and nondetection error (cf. Pedersen and Boomsma 1999) raised the Uppsala estimate to $14.1 \%$. 
TABLE 3. Average regression-relatednesses, frequency of worker reproduction, and reproductive value ratios in the three Lasius niger samples. Standard errors are given in parentheses.

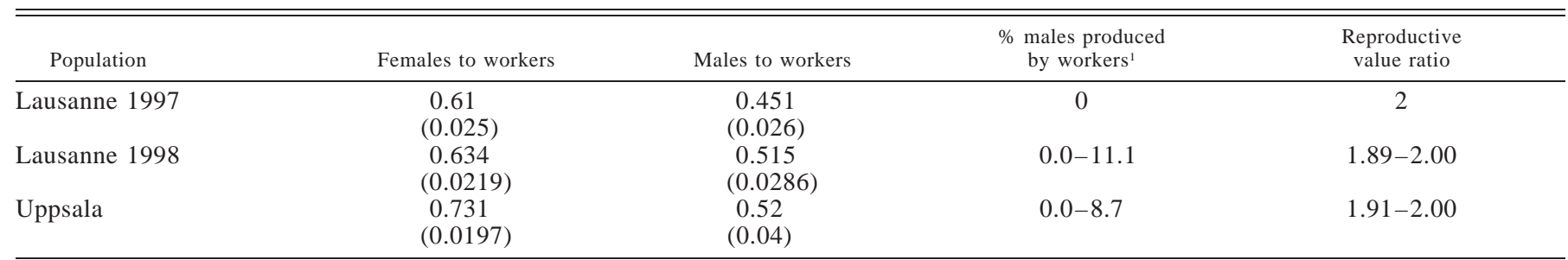

\footnotetext{
${ }^{1}$ Upper estimate obtained using equation (2), assuming that the nonsignificant deviations from 0.50 of the male to worker relatedness did indicate worker
} reproduction.

$$
r_{m f}=0.50(1-q)+q r_{f f}
$$

where $q$ is the proportion of males that are worker produced. For all analyses we assumed that the relatedness of males to workers $\left(r_{m w}\right)$ was the same as the relatedness of males to gynes $\left(r_{m f}\right)$ regardless of which of the two was estimated.

We estimated the female-male reproductive value ratio (a function of the female-male ploidy ratio and the frequency of worker reproduction) as $v_{f} / v_{m}=2-q$ (Crozier and Pamilo 1996), obtaining subsequently the relatedness asymmetry as $R A=\left(r_{f f} / r_{m f}\right)\left(v_{f} / v_{m}\right)$ (Boomsma and Grafen 1991; Bourke and Franks 1995; Crozier and Pamilo 1996).

\section{Sex Allocation Tests}

For each population sample we estimated the optimal allocation in females in single-paternity colonies by the ratio between the average $[R A /(R A+1)]$ and the population frequency of single-paternity colonies (Boomsma and Grafen 1991 ), where the average $R A$-values were based on IBD analyses (Goodnight 1999). From the predictions for the singlepaternity classes, we derived the prediction for the multiplepaternity class for each population sample (as in Boomsma and Grafen 1991). Unbiased estimates of the means and pseudovalue distributions for the expected investments were obtained by jackknifing over colonies to repeatedly estimate $v_{f} /$ $v_{m}$ from the population mean $r_{f f}$ and $r_{f m}$, the paternity-classspecific $r_{f f}$ and $r_{f m}$, and the frequency of the two paternity classes.

The expected fitness benefit to multiply mated queens was estimated as

$$
\begin{aligned}
W_{\text {multiple }} / W_{\text {single- }}= & {\left[\left(m_{\text {multiple- }} / M\right)+\left(f_{\text {multiple }} / F\right)\right] } \\
& \div\left[\left(m_{\text {single }} / M\right)+\left(f_{\text {single }} / F\right)\right],
\end{aligned}
$$

where $M$ and $F$ are the population average proportional allocations to males and females that would be optimal for workers of the balancing class (sensu Boomsma and Grafen 1991) and $m$ and $f$ are the allocations to males and females by workers of a given paternity class (modified after eq. 2 in Sundström and Ratnieks 1998). This equation assumes that there are no productivity differences among single- and multiple-paternity classes. We verified this assumption.

For each population and year, we tested whether the observed investments in females fit the class-specific predictions for single- and multiple-paternity classes and whether the observed investments differed between paternity classes. We also tested for a correlation between investment in fe- males and relatedness asymmetry at the colony level. Because workers might assess relatedness asymmetry on the basis of the genetic diversity among workers, we additionally tested for an association between sex allocation and the relatedness among female nestmates (cf. Aron et al. 1999).

Because the proportional investment in females is associated with colony productivity in many ant species (Nonacs 1986a,b) we tested for such an association and examined whether controlling for productivity affected the outcome of our tests. Finally, we tested whether workers were controlling sex allocation only at the population level, estimating the expected investment in females from the population-mean relatedness asymmetry, $f=R A /(R A+1)$ (Trivers and Hare 1976; Crozier and Pamilo 1996). We used jackknifing over colonies to obtain bias-corrected estimates of the expected mean investments in females and pseudovalue distributions (cf. van der Have et al. 1988; Pearson et al. 1995, 1997). The average investment in females was estimated both as the mean of colony means and as the mean of productivityweighted colony means (the so-called lumped mean; Bourke and Franks 1995), calculated as:

$$
\sum f_{a} /\left(\sum f_{a}+\sum m_{a}\right)
$$

where $f_{a}$ and $m_{a}$ are the absolute, metabolically corrected investments in females and males made by individual colonies, and the summation is over all colonies. Note that this differs from Bourke and Franks (1995, pp. 160-161), where the metabolical correction is incorrectly applied to the numerator only.

\section{RESULTS}

\section{Genetic Structure of Colonies}

Multiple paternity was rare in Uppsala (seven of 52 colonies) but frequent in Lausanne (16 of 27 and 21 of 34, in Lausanne 1997 and 1998, respectively), where five cases of triple matings and one case of quadruple mating were detected (Table 2). Pedigree and IBD estimates of effective paternity frequency were very similar (Table 2), as were estimates of the relatedness between female nestmates; therefore, we present only IBD based relatedness estimates (Table 3).

In the Lausanne 1997 sample, the genotypes of all males were compatible with their being offspring of the queen. In contrast, three of 133 males and six of 372 males in the Lausanne 1998 and Uppsala samples, respectively, could not have been produced by queens but were compatible with 
TABLE 4. Investments in female and male sexuals and total investments in sexuals as estimated by trapping (Lausanne) or excavation (Uppsala). Ranges are given in parentheses.

\begin{tabular}{lccc}
\hline \hline \multicolumn{1}{c}{ Population } & $\begin{array}{c}\text { Average } \\
\text { number of } \\
\text { females }\end{array}$ & $\begin{array}{c}\text { Average } \\
\text { number of } \\
\text { males }\end{array}$ & $\begin{array}{c}\text { Average total } \\
\text { sexual biomass } \\
(\mathrm{mg})\end{array}$ \\
\hline Lausanne 1997 & 279 & 1692 & 7909 \\
Lausanne 1998 & $(0-1065)$ & $(0-5909)$ & $(121-29,260)$ \\
Uppsala & 191 & 1255 & 5250 \\
& $(0-877)$ & $(0-5538)$ & $(194-23,571)$ \\
& 263 & 1024 & 6121 \\
& $(0-1990)$ & $(0-5102)$ & $(308-37,403)$ \\
\hline
\end{tabular}

${ }^{1}$ Corrected for the different metabolic rates of females and males.

worker reproduction. All these males were from colonies also producing gynes, that is, colonies that contained a functional queen.

None of the estimates of male to female nestmate relatednesses were significantly different from the value expected when queens produce all males (0.50; Table 3$)$. However, this lack of power of test is not surprising when worker reproduction is rare. We used $r_{m f}$ and equation (2) to estimate the maximum value of worker reproduction (Table 3 ). These values fit fairly well with the estimates based on pedigree analysis, except for the Uppsala $q_{I B D}$, which was 3.8 times higher than the pedigree estimate. For Lausanne 1997 the estimated $r_{m f}$ was lower (but not significantly so) than 0.50 (Table 3). A $r_{m f}$-value lower than 0.50 cannot stem from worker reproduction when the observed $r_{f f}$ is above 0.50 (see eq. 2). Therefore, our maximum IBD estimate of worker reproduction was zero for Lausanne 1997.

\section{Sex Allocation}

For both populations and years, on average, colonies produced more than 1000 males and almost 200 females (Table 4). The investment in females varied substantially among colonies (coefficients of variation: $66 \%, 57 \%$, and $57 \%$, for Lausanne 1997, 1998, and Uppsala, respectively) but few colonies produced only one sex (eight of 95 colonies produced only gynes and three colonies only males). There were no productivity differences between single- and multiple-paternity colonies (P. J. Gertsch, E. J. Fjerdingstad, and L. Keller, unpubl. ms.).

Relatedness asymmetry varied substantially between single- and multiple-paternity colonies (Table 5). If workers manipulated colony sex allocation as predicted, the estimated increase in queen fitness gained through multiple mating would be 1.7 fold in Lausanne (both years) and 2.1 fold in Uppsala. However, contrary to split sex-ratio theory predictions, there was no significant association between paternity class and relative investment in males and females (Table 5; Fig. 1). Workers in single-paternity colonies in both Lausanne and Uppsala invested far more than predicted in males, whereas workers in multiple-paternity colonies in Uppsala invested too much in females (Table 5). Multiple-paternity colonies in Lausanne also produced more females than predicted, although not significantly so (Table 5).

When looking at colonies individually instead of grouping them into paternity classes, once again there was no evidence

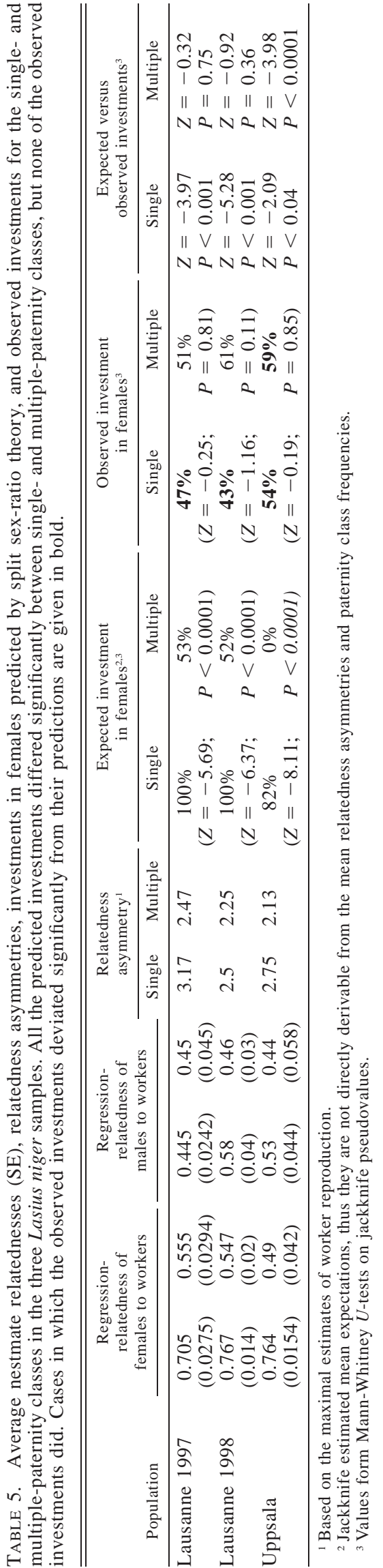



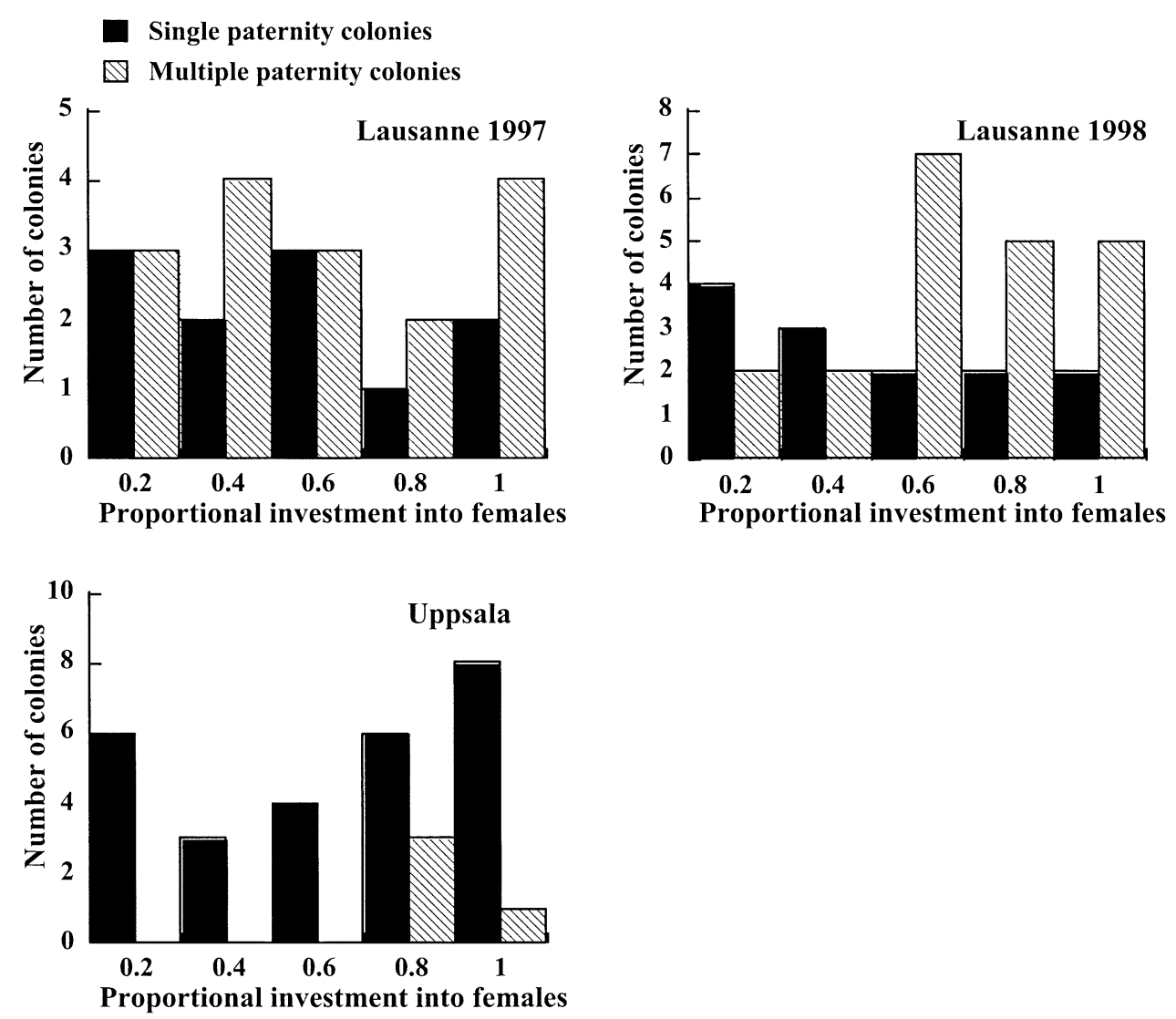

FIG. 1. The proportional investment in females by single- and multiple-paternity classes in the three Lasius niger population samples. Differences between classes were not significant (Table 5; Lausanne combined $P=0.31$, cf. Fisher in Sokal and Rohlf 1995, pp. 794-797). Multiple-paternity colonies tended to invest more, not less, in females than did single-paternity colonies (mean investment of singleand multiple-paternity classes: Lausanne 1997: 0.47, 0.51; Lausanne 1998: 0.43, 0.61; Uppsala: 0.54, 0.59).

for any positive association between investment in females and colony-specific relatedness asymmetry (Table 6). In fact, the trend in Lausanne in 1997 was for colonies with a high relatedness among nestmate females to invest less in female production. This association, however, did not remain significant when correcting for multiple tests.

There was no clear association between colony productivity and investment in females. In the two Lausanne populations the association was not significant (Fig. 2a, b). In

TABLE 6. Correlation of colony investment in females with relatedness asymmetry and relatedness among female nestmates. Productivity-corrected values are given in parentheses and significant values are presented in bold.

\begin{tabular}{lccccc}
\hline \hline \multirow{2}{*}{ Population } & \multicolumn{2}{c}{$\begin{array}{c}\text { Life-for-life } \\
\text { relatedness asymmetry }\end{array}$} & & \multicolumn{2}{c}{$\begin{array}{c}\text { Female nestmate } \\
\text { regression-relatedness }\end{array}$} \\
\cline { 2 - 3 } \cline { 5 - 6 } Lausanne 1997 & $t^{1}$ & $P^{2}$ & & $t^{1}$ & $P^{2}$ \\
\hline & -0.01 & 0.98 & & -0.26 & $\mathbf{0 . 0 5}$ \\
Lausanne 1998 & $(-0.03)$ & $(>0.40)$ & & $(-0.14)$ & $(<0.20)$ \\
& $(-0.05$ & 0.68 & & -0.12 & 0.31 \\
Uppsala & $(-0.05)$ & $(>0.35)$ & & $(-0.17)$ & $(<0.10)$ \\
& $(-0.09$ & 0.53 & & 0.01 & 0.94 \\
& $(-0.06)$ & $(>0.30)$ & & $(-0.11)$ & $(<0.20)$ \\
\hline
\end{tabular}

\footnotetext{
' Kendall rank correlation and partial rank correlation.

${ }^{2} P$-values in parentheses were estimated by extrapolation from Siegel and Castellan's (1988) table S.
}

Uppsala there was a significant positive relationship, but this did not hold up when correcting for multiple tests (Fig. 2c). Even so, we investigated whether controlling for productivity would affect our conclusions, which was not the case. The proportional investment in females remained uncorrelated with both relatedness asymmetry and female nestmate relatedness after controlling for colony productivity (Table 6).

At the population level, the observed investment in females was significantly lower than expected under worker control for each of the three samples (Table 7). This was also significant when using lumped means (productivity corrected means), except for Uppsala (Table 7). In contrast, none of the observed population-average investments in females differed significantly from the predicted queen optimum of 0.50 (Table 7).

Very similar results were obtained for all sex allocation tests when using pedigree-based estimates of the effective number of mates per queen and pedigree relatedness estimates.

\section{DISCUSSION}

Our genetic analyses showed that multiple mating by queens occurred at a relatively low frequency in Uppsala (13.5\%) and was very common (59.3-61.8\%) in Lausanne. In both populations, all or almost all colonies were headed 

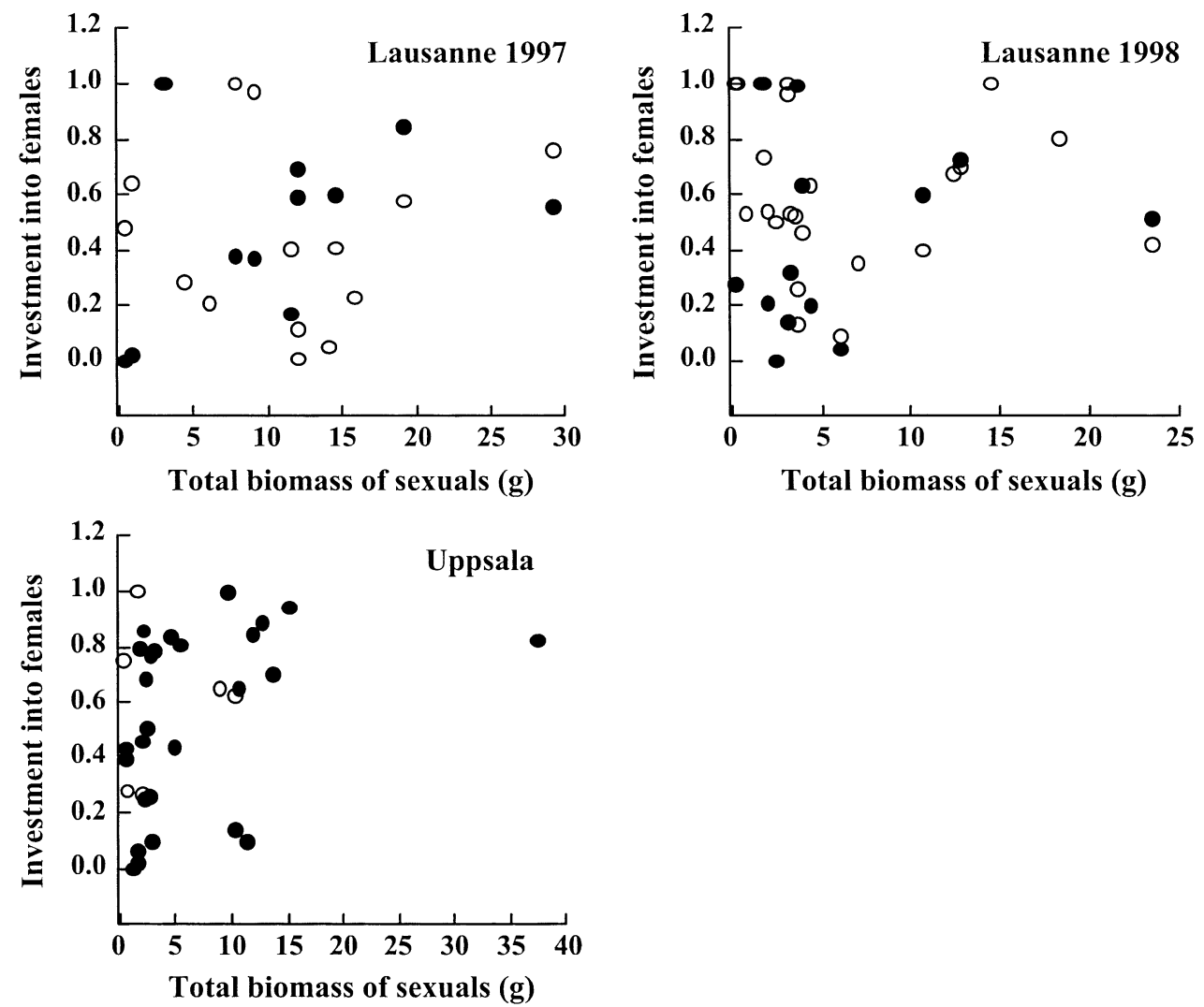

FIG. 2. Proportional investment in females and total investment in sexuals for the three Lasius niger population samples (black circles represent single-paternity colonies, white multiple-paternity colonies). The relationship was not significant for any sample after correcting for multiple tests (Kendall rank correlations, Bonferroni-corrected significance limit $\alpha=0.017$; Lausanne 1997: $t=0.24, n=28$ colonies, $P=0.07$; Lausanne 1998: $t=-0.08, n=34$ colonies, $P=0.65 ; P_{\text {combined, Lausanne }}=0.20 ;$ Uppsala: $t=0.27, n=33$ colonies, $P=$ $0.03)$.

by a single queen and workers contributed very little to male parentage. This breeding system translated into marked differences in relatedness asymmetry. Substantial variation in sex allocation existed among colonies, as found also by van der Have et al. (1988) for Dutch populations of L. niger; but, contrary to split sex-ratio theory expectations, this variation was not correlated with relatedness asymmetry. Single- and multiple-paternity colonies invested, on average, the same proportion of resources in females instead of producing, respectively, mainly females and mainly males.

Because colony sex ratios were not linked with queen mating frequency, multiply mated L. niger queens did not achieve any sex-ratio benefits over single-mated queens even though their fitness could have been up to 2.1 times higher had workers biased sex allocation according to split sex-ratio predictions. Moreover, population-mean sex ratios were at or very

TABLE 7. Investments in females expected under worker or queen control at the population level and the observed investments. The 95\% confidence limits are given in parentheses; significant values are presented in bold.

\begin{tabular}{|c|c|c|c|c|c|c|c|c|}
\hline \multirow[b]{3}{*}{ Population } & \multicolumn{2}{|c|}{$\begin{array}{l}\text { Expected investment } \\
\text { in females }{ }^{1}\end{array}$} & \multirow{3}{*}{$\begin{array}{c}\text { Observed investment } \\
\text { in females: } \\
\text { Mean of colony } \\
\text { means } \\
\text { Lumped mean }{ }^{2}\end{array}$} & \multirow{2}{*}{\multicolumn{2}{|c|}{$\mathrm{H}_{0}=$ worker control }} & \multirow{2}{*}{\multicolumn{3}{|c|}{$\mathrm{H}_{0}=$ queen control }} \\
\hline & \multirow{2}{*}{$\begin{array}{l}\text { Worker } \\
\text { control }\end{array}$} & \multirow{2}{*}{$\begin{array}{l}\text { Queen } \\
\text { control }\end{array}$} & & & & & & \\
\hline & & & & $Z^{3}$ & $P^{4}$ & $t_{Q}{ }^{5}$ & df & $P$ \\
\hline \multirow[t]{2}{*}{ Lausanne 1997} & $0.73(0.70-0.76)$ & 0.50 & $0.50(0.37-0.63)$ & -3.27 & 0.001 & 0 & 28 & 1 \\
\hline & & & $0.56^{2}$ & -2.24 & 0.025 & & & \\
\hline \multirow[t]{2}{*}{ Lausanne 1998} & $0.72(0.64-0.79)$ & 0.50 & $0.54(0.43-0.65)$ & -2.58 & 0.010 & 0.84 & 33 & 0.42 \\
\hline & & & $0.54^{2}$ & -3.40 & 0.0007 & & & \\
\hline \multirow[t]{2}{*}{ Uppsala } & $0.73^{2}$ & 0.50 & $0.55(0.44-0.66)$ & -2.35 & 0.019 & 0.93 & 32 & 0.36 \\
\hline & & & $0.66^{2}$ & -1.44 & 0.15 & & & \\
\hline
\end{tabular}

${ }^{1}$ Based on jackknifing and therefore not directly derivable from mean relatednesses and reproductive value ratios.

${ }^{2}$ Confidence intervals could not be constructed because the distribution(s) deviated strongly from normality.

${ }^{3}$ From Mann-Whitney $U$-tests.

${ }^{4}$ All significant values remain significant after correcting for multiple tests.

5 Student $t$-test. 
close to the queen optimum (0.50). Thus, there was no fitness incentive for queens to attempt to change colony sex ratios, and queens heading male-producing colonies did not gain any benefits over queens heading colonies producing females (at the queen optimum, all colony sex ratios bring equal fitness to queens; review by Crozier and Pamilo 1996). Our results were consistent across years for two independent subsamples of the same Lausanne population and across widely separated populations differing substantially in average queen mating frequency.

There was no evidence that our estimates of the optimal sex ratios for L. niger workers and queens in our populations were confounded by incorrect estimations of mating system parameters. For three colonies (Lausanne 1997) more than one queen might have contributed to the female brood, although the most likely explanation for the observed genotypes was probably the incorporation of foreign gynes that had landed on traps. Even if multiple maternity did occur, however, the conclusions of our sex allocation tests would remain the same. Our tests were based on IBD estimates of nestmate relatednesses, which make no assumptions about pedigree structure. The slight increase in male reproductive value brought about by the inferred worker reproduction would, however, disappear if multiple queens, not workers, were responsible for the observed male genotypes. Therefore, the expected population-mean sex allocation would become slightly more female biased, that is, even more different from the observed investment.

Local resource competition (reviews by Bourke and Franks 1995; Crozier and Pamilo 1996) could in theory have decreased the value of females in our populations, making the optimal population-mean sex ratio for workers less female biased. However, the biology of L. niger makes this very unlikely. This species has large nuptial flights in which sexuals from probably hundreds to thousands of colonies take part and sexuals are strong fliers (E. J. Fjerdingstad, pers. obs.) and likely disperse several kilometers. Indeed $F_{\mathrm{ST}}$ is close to zero between distant populations (Boomsma and van der Have 1998), and there is no evidence that genotypes of young queens collected after a mating flight depart from Hardy-Weinberg proportions (E. J. Fjerdingstad, P. J. Gertsch, and L. Keller, unpubl. data). It therefore seems highly improbable that related queens would compete with each other (see also van der Have et al. 1988).

Moreover, it is not likely that our results were affected by a sampling bias. Boomsma et al. (1982) found a positive association between the investment in females and total productivity of colonies (if the variables had been corrected for the differential metabolic cost this association might have disappeared). However, it is highly unlikely that by chance we sampled from low productivity, resource-poor colonies that were shunting all diploids eggs in workers and thus producing few females (reviews by Rosenheim et al. 1996; Bourke and Franks 1995; Crozier and Pamilo 1996) because the productivities of our colonies were 1.5-6.0 (females) and 2.8-4.9 (males) times higher than the ones found by Boomsma et al. (1982) for Dutch populations. Also, as stated, we found no relationship between productivity and investment in females in our populations, except for a marginal one in Uppsala.
Population-mean sex investment ratios in Lausanne and Uppsala were very close to the queen's optimum, which is counter to the report that sex ratios in several populations of Dutch L. niger fit well with the values expected under worker control (van der Have et al. 1988). However, van der Have et al. (1988) may have overestimated the frequency of worker reproduction leading to an underestimation of the expected female bias. For all colonies in which any worker-produced male was found, they assumed all males to be worker produced. Also, they weighted the frequency of worker reproduction by colony productivity without demonstrating a significant association between the two variables. Moreover, for one of their populations all males produced in four large male-producing colonies were apparently assumed to be all worker produced without seeking genetic confirmation thereof. This will have contributed to bringing the expected worker-optimal sex allocation for that population close to $1: 1$, making it fit well with the slightly male-biased sex-ratio investment observed (47\% females).

Our finding no sex-ratio benefits for queens that mate multiply contrasts with the strong support found for the sex-ratio manipulation hypothesis in the ant $F$. truncorum (Sundström and Ratnieks 1998), where multiply mated queens experience an almost $40 \%$ higher fitness due to sex-ratio benefits (whether this is enough to compensate for costs of mating multiply remains unknown). Also, our results contrast with the numerous findings that social hymenopteran workers bias sex allocation at the colony level in response to relatedness asymmetry (reviews by Queller and Strassmann 1998; Chapuisat and Keller 1999). However, our study is not the first to provide negative results for split sex-ratio theory, such having been reported for several ant species that vary in queen number (review by Chapuisat and Keller 1999), for example, Pheidole pallidula (Aron et al. 1999) and Formica exsecta (Brown and Keller 2000). Nor are we the first to find population-mean sex ratios inconsistent with worker control such having been reported by Helms (1999) and Pearson et al. (1997) for the ants Pheidole desertorum and Leptothorax tuberum, respectively (see also table 5.11 in Bourke and Franks 1995). Recent empirical and theoretical studies also show that queens can have partial or even full control over colony sex ratios under some ecological conditions (Passera et al. 2001; Reuter and Keller 2001).

Lasius niger workers in our populations may have lacked accurate genetic cues to assess intracolonial relatedness asymmetry or cues to distinguish between male and female larvae, with the effect that there would have been too much error and no benefit from biasing colony sex ratios (Boomsma and Grafen 1991; Ratnieks and Boomsma 1995, 1997; review by Chapuisat and Keller 1999). Alternatively, L. niger sexual and worker brood may arise from temporally separated batches of eggs (Forel 1920), as is the case in several other ants (Brian 1983), which could allow queens to control colony sex allocation by limiting the number of fertilized (female) eggs laid in the sexual batch (Passera et al. 2001; Reuter and Keller 2001). Such a limitation on female eggs would leave workers with no better option than to also rear the male eggs available (Reuter and Keller 2001).

In summary, our study on two populations of $L$. niger provided no evidence that workers control sex allocation, 
neither at the colony nor at the population level. Because the population-mean sex allocation was very close to the queen optimum, queen fitness did not depend on colony sex ratio and so there was no fitness incentive for queens to attempt to change sex allocation. Moreover, colony sex ratios were not associated with queen mating frequency. Thus, the sexratio manipulation theory (Ratnieks and Boomsma 1995) cannot account for the occurrence of multiple mating in L. niger. Although the sex-ratio manipulation theory provides a potentially strong selective pressure favoring multiple mating, our work suggests that its intimate reliance on sophisticated sex allocation control by workers may limit the power of this hypothesis to explain the existence of multiple mating in social Hymenoptera in general.

\section{ACKNOWLEDGMENTS}

We thank A. Andersson, Y. Chuat, C. Koenig, J. Kohler, M. J. B Krieger, M. Ménétrey, C. Olsson, M. Reuter, and C. Roger for assistance in the field or laboratory; B. Seifert for taxonomical advice; M. A. D. Goodisman for discussion; and J. J. Boomsma, R. Brooks, R. H. Crozier, J. S. Pedersen, and two anonymous reviewers for comments on the paper. EJF was supported by the Carlsberg Foundation (Copenhagen, Denmark), PG by the Swedish Natural Science Research Council, and LK by several grants from the Swiss NSF.

\section{Literature Cited}

Aron, S., E. Campan, J. J. Boomsma, and L. Passera. 1999. Social structure and split sex ratios in the ant Pheidole pallidula. Ethol. Ecol. Evol. 11:209-227.

Baer, B., and P. Schmid-Hempel. 1999. Experimental variation in polyandry affects parasite loads and fitness in a bumble-bee. Nature 397:151-154.

Birkhead, T. R., and A. P. Møller, eds. 1998. Sperm competition and sexual selection. Academic Press, San Diego, CA.

Boomsma, J. J., and A. Grafen. 1991. Colony-level sex ratio selection in the eusocial Hymenoptera. J. Evol. Biol. 4:383-407.

Boomsma, J. J., and J. A. Isaaks. 1985. Energy investment and respiration in queens and males of Lasius niger (Hymenoptera: Formicidae). Behav. Ecol. Sociobiol. 18:19-27.

Boomsma, J. J., and F. L. W. Ratnieks. 1996. Paternity in eusocial Hymenoptera. Philos. Trans. R. Soc. Lond. B 351:947-975.

Boomsma, J. J., and T. M. van der Have. 1998. Queen mating and paternity variation in the ant Lasius niger. Mol. Ecol. 7: 1709-1718.

Boomsma, J. J., G. A. van der Lee, and T. M. van der Have. 1982 On the production ecology of Lasius niger (Hymenoptera: Formicidae) in successive coastal dune valleys. J. Anim. Ecol. 51: 975-991.

Bourke, A. F. G., and N. R. Franks. 1995. Social evolution in ants. Princeton Univ. Press. Princeton, NJ.

Brian, M. V. 1983. Social insect ecology and behavioural biology. Chapman and Hall, London.

Brown, W. D., and L. Keller. 2001. Colony sex ratios vary with queen number but not relatedness asymmetry in the ant Formica exsecta. Proc. R. Soc. London. B 267:1751-1757.

Chapuisat, M., and L. Keller. 1999. Testing kin selection with sex allocation data in eusocial Hymenoptera. Heredity 82:473-478.

Cole, B. J. 1983. Multiple mating and the evolution of social behaviour in the Hymenoptera. Behav. Ecol. Sociobiol. 12: 191-201.

Cole, B. J., and D. C. Wiernasz. 1999. The selective advantage of low relatedness. Science 285:891-893.

Crozier, R. H., and E. J. Fjerdingstad. 2001. Polyandry in eusocial Hymenoptera: Disunity in diversity? Ann. Zool. Fenn. 38: $267-285$.
Crozier, R. H., and P. Pamilo. 1996. Evolution of social insect colonies: sex allocation and kin selection. Oxford Univ. Press, Oxford, U.K.

Fjerdingstad, E. J., and J. J. Boomsma. 1998. Multiple mating increases the sperm stores of Atta colombica leafcutter ant queens. Behav. Ecol. Sociobiol. 42:257-261.

Fjerdingstad, E. J., and L. Keller. 2000. The nature of ant colony success. (Technical comment). Science 287(5457):1363b.

Fjerdingstad, E. J., J. J. Boomsma, and P. Thoren. 1998. Multiple paternity in the leafcutter ant Atta colombica: a microsatellite DNA study. Heredity 80:118-126.

Forel, A. 1920. Les Fourmis de la Suisse. Imprimérie coopérative. La Chaux-de-Fonds, Switzerland.

Goodnight, K. F. 1999. Relatedness. Ver. 5.05. Available via http: //gsoft.smu.edu/GSoft.html.

Hamilton, W. D. 1964. The genetical evolution of social behaviour. I, II. J. Theor. Biol. 7:1-52.

Helms, K. R. 1999. Colony sex ratios, conflict between queens and workers, and apparent queen control in the ant Pheidole desertorum. Evolution 53:1470-1478.

Jennions, M. D., and M. Petrie. 2000. Why do females mate multiply? A review of the genetic benefits. Biol. Rev. Camb. Philos. Soc. 75(1):21-64.

Keller, L., and H. K. Reeve. 1994. Genetic variability, queen number, and polyandry in social hymenoptera. Evolution 48: 694-704.

_ - 1995. Why do females mate with multiple males? The sexually selected sperm hypothesis. Adv. Study Behav. 24: 291-315.

Kraus, B., and R. E. Page. 1998. Parasites, pathogens, and polyandry in social insects. Am. Nat. 151:383-391.

Moritz, R. F. A. 1985. The effect of multiple mating on the workerqueen conflict in Apis mellifera. Behav. Ecol. Sociobiol. 16: 375-377.

Nonacs, P. 1986a. Ant reproductive strategies and sex allocation theory. Q. Rev. Biol. 61:1-21.

- 1986b. Sex-ratio determination within colonies of ants. Evolution 40:199-204.

Page, R. E. 1986. Sperm utilization in social insects. Annu. Rev. Entomol. 31:297-320.

Pamilo, P. 1991. The evolution of colony characteristics in social insects. II. Number of reproductive individuals. Am. Nat. 138: 412-433.

_ 1993. Polyandry and allele frequency differences between the sexes in the ant Formica aquilonia. Heredity 70:472-480.

Passera, L., S. Aron, E. L. Vargo, and L. Keller. 2001. Queen control of sex ratio in fire ants. Science 293(5533):1308-1310.

Pearson, B., A. F. Raybould, and R. T. Clarke. 1995. Breeding behaviour, relatedness and sex-investment ratios in Leptothorax tuberum Fabricius. Entomol. Exp. Appl. 75:165-174.

Pearson, B., A. F. Raybould, and R. T. Clarke. 1997. Temporal changes in the relationship between observed and expected sexinvestment frequencies, social structure and intraspecific parasitism in Leptothorax tuberum (Formicidae). Biol. J. Linn. Soc. 61:515-536.

Pedersen, J. S., and J. J. Boomsma. 1999. Multiple paternity in social Hymenoptera: estimating the effective mate number in single-double mating populations. Mol. Ecol. 8:577-587.

Queller, D. C. 1993. Worker control of sex ratios and selection for extreme multiple mating by queens. Am. Nat. 142:346-351.

Queller, D. C., and K. F. Goodnight. 1989. Estimating relatedness using genetic markers. Evolution 43:258-275.

Queller, D. C., and J. E. Strassmann. 1998. Kin selection and social insects. Bioscience 48:165-175.

Ratnieks, F. L. W., and J. J. Boomsma. 1995. Facultative sex allocation by workers and the evolution of polyandry by queens in social Hymenoptera. Am. Nat. 145:969-993.

_ 1997 . On the robustness of split sex ratio predictions in monogynous social Hymenoptera. J. Theor. Biol. 185:423-439.

Raymond, M., and F. Rousset. 1995. GENEPOP. 1.2: A population genetics software for exact tests and ecumenism. J. Heredity. $86: 248-249$. 
1997. GENEPOP. Rel. 3.1. Montpellier University, France. Reuter, M., and L. Keller. 2001. Sex ratio conflict and worker production in eusocial Hymenoptera. Am. Nat. 158:166-177.

Rosenheim, J. A., P. Nonacs, and M. Mangel. 1996. Sex ratios and multifaceted parental investment. Am. Nat. 148:501-535.

Schmid-Hempel, P. 1998. Parasites in social insects. Princeton Univ. Press. Princeton, NJ.

Seifert, B. 1996. Ameisen, beobachten, bestimmen. Naturbuch Verlag, Weltbild Verlag GmbH, Augsburg, Germany.

Siegel, S., and N. J. Castellan Jr. 1988. Nonparametric statistics for the behavioral sciences. 2d ed. McGraw-Hill Book Company, New York.

Sherman, P. W., T. D. Seeley, and H. K. Reeve. 1998. Parasites, pathogens, and polyandry in honey bees. Am. Nat. 151:392-396.
Sokal, R. R., and F. J. Rohlf. 1995. Biometry. 3rd ed. W. H. Freeman and Company, New York.

Sundström, L. 1994. Sex ratio bias, relatedness asymmetry and queen mating frequency in ants. Nature 367:266-268.

Sundström, L., and F. L. W. Ratnieks. 1998. Sex ratio conflicts, mating frequency, and queen fitness in the ant Formica truncorum. Behav. Ecol. 9:116-121.

Trivers, R. L., and H. Hare. 1976. Haplodiploidy and the evolution of the social insects. Science 191:249-263.

van der Have, T. M., J. J. Boomsma, and S. B. J. Menken. 1988. Sex-investment ratios and relatedness in the monogynous ant Lasius niger (L.). Evolution 42(1):160-172.

Zar, J. H. 1996. Biostatistical analysis. 2d ed. Prentice Hall, London.

Corresponding Editor: D. Wheeler 